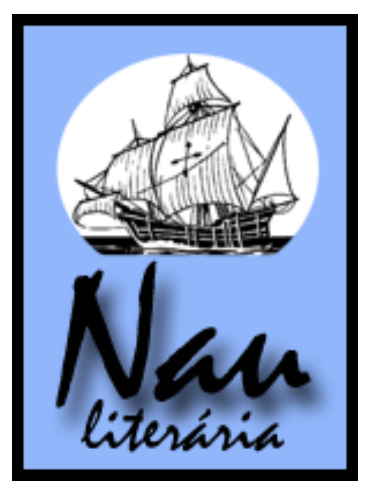

\title{
O reino de Benjamim por um olhar pós-colonial ${ }^{1}$
}

\section{Cristina Arena Forli ${ }^{2}$}

\begin{abstract}
Resumo: Este trabalho tem como objeto de estudo o romance $O$ nosso reino, de Valter Hugo Mãe, publicado em 2004. Benjamim, um menino de oito anos, é quem conduz a narração, a qual é norteada por sua memória. Esta evidencia sua visão infantil do mundo, ao mesmo tempo em que também revela a memória coletiva da nação de que faz parte. Assim, o objetivo desta pesquisa é analisar a construção da identidade do colonizador português a partir da narração desse menino. Os resultados demonstram que a narração de Benjamim carrega consigo a ambivalência dessa identidade.
\end{abstract}

Palavras-chave: Identidade; pós-colonialismo; memória; Valter Hugo Mãe; O nosso reino.

\begin{abstract}
This article has as its object of study the novel $O$ nosso reino, by Valter Hugo Mãe, published in 2004. Benjamim, a boy of eight years old, is who leads the narration, which is guided by his memory. Its memory evidences their infantile wordlview while also reveals the colletive memory of the nation that is part. Therefore, the objective of this study is to analyze the construction of the identity of the Portuguese colonizer from the narration of this boy. The results shows that the narration of Benjamim carries the ambivalence of that identity.
\end{abstract}

Key-words: Identity; post-colonialism; memory; Valter Hugo Mãe; O nosso reino.

\section{Considerações iniciais}

Sendo um meio de reter dados da percepção, da experiência e, ainda, um meio de evocar esses mesmos dados, a memória revela um dos principais sentidos da existência humana, que é a relação com o tempo. Ela confere sentido ao passado, de forma a possibilitar que o sujeito o reconstrua a partir do tempo presente. A literatura, nesse âmbito, representa um significativo campo de vivências, tanto coletivas quanto individuais, em que as memórias são narradas e apresentam uma abordagem de entrelaçamento entre o que é real e o que é ficcional, na medida em que fazem um diálogo com a história.

Para Maurice Halbwachs (2006), a memória de um sujeito não é somente sua, permanecendo as lembranças sempre coletivas. Isso ocorre, de acordo com o estudioso, porque jamais se está só. Um sujeito sempre carrega consigo "uma quantidade de pessoas que não se confundem" (2006, p. 30). A memória individual constitui-se, assim, um ponto de vista sobre a memória coletiva. É por meio da memória que são construídas as representações culturais. A história, e também a identidade, estão condicionadas à memória. Nesse sentido,

\footnotetext{
${ }^{1}$ Este trabalho está vinculado ao projeto de pesquisa "Os discursos literários das nações africanas", coordenado pelo Prof ${ }^{\circ}$ Dr. Luís Marozo.

${ }^{2}$ Mestranda em Literaturas Portuguesa e Luso-Africana pelo Programa de Pós-Graduação em Letras da UFRGS.
} 
este trabalho tem como objeto de estudo $O$ nosso reino, primeiro romance do escritor nascido em Angola Valter Hugo Mãe, publicado pela primeira vez em 2004. O romance tem como fio condutor a memória do menino Benjamim, que revela, em consonância com as ideias de Halbwachs, a memória coletiva da sociedade da qual faz parte, pré e pós-25 de Abril.

Os estudos referentes à memória e os estudos pós-coloniais têm em comum o fato de voltarem-se para o passado a fim de buscar uma reavaliação deste. Desse modo, pretende-se analisar, a partir de uma perspectiva dos estudos pós-coloniais, em que medida a identidade do colonizador português pode ser evidenciada na narração memorialística de Benjamim.

\section{A possibilidade de uma história outra}

Tendo em vista a perspectiva que se escolheu seguir para a realização da referida análise, cabe a discussão acerca do pós-colonial. Esse termo, após a Segunda Guerra, tem um sentido cronológico e é utilizado para designar os países recém independentes. Depois dos anos 1970, seu sentido muda e passa então a ser usado para discutir os efeitos culturais causados pela colonização, abrangendo experiências que se deslocam no tempo e se situam em diferentes lugares. Dessa forma, percebe-se que a pluralidade é uma constante nesse campo.

Russel Hamilton (1999), em "A literatura dos PALOP e a teoria pós-colonial”, traz a discussão de Appiah (1997) sobre o prefixo "pós” entre os termos "pós-colonialismo" e "pósmodernismo" a fim de verificar se os dois apresentam os mesmos significados. A conclusão a que este último teórico chega é a de que ambos os "pós" são iguais no que diz respeito à necessidade de abrir novos espaços. No entanto, também conclui que são diferentes porque o pós-modernismo está ligado à vanguarda estética. Ele supera a estética moderna e problematiza o pensamento moderno. O pós-colonialismo, por outro lado, carrega consigo uma "carga de significadores e referentes políticos e sócio-econômicos" (HAMILTON, 1999, p. 17). Volta seu olhar para o passado enquanto caminha para o futuro, pretendendo frustrar os discursos coloniais. Assim, repensar o passado constitui-se uma das estratégias fundamentais para a compreensão das questões levantadas por essa esfera teórica.

O pós-colonialismo provoca questionamentos acerca dos sujeitos que têm legitimidade para falar nos contextos coloniais, da perspectiva que se assume e sobre o lugar de onde se fala. Ele reivindica outro locus de enunciação, de forma a deslocar os centros de poder, conforme afirma Walter Mignolo (1996). Nesse sentido, os estudos de Foucault (1996) sobre a produção de discurso e os jogos de poder que a envolvem constituem-se contribuição fundamental. Esse teórico dá destaque para os procedimentos de exclusão, que têm por função 
organizar e redistribuir a produção dos discursos, pois, sendo o discurso o que traduz as lutas e também aquilo pelo que se luta, são estabelecidas formas de deslegitimar determinadas falas (FOUCAULT, 1996). Assim, o pós-colonial surge num movimento de tomar a alteridade como ponto de partida, de colocar em evidência histórias outras que não as que são impostas pelas instituições de poder colonial.

Stuart Hall (2003), em seu Da diáspora - identidades e mediações culturais, explica que esse termo não se limita à descrição de uma época ou sociedade. Para o teórico,

Ele relê a "colonização" como parte de um processo global essencialmente transnacional e transcultural - e produz uma reescrita descentrada, diaspórica ou "global" das grandes narrativas imperiais do passado, centradas na nação. Seu valor teórico, portanto, recai precisamente sobre sua recusa de uma perspectiva do "aqui" e "lá", de um "então" e "agora", de um "em casa" e "no estrangeiro" (HALL, 2003, p. 109).

Essas narrativas imperiais de que fala o teórico eram centradas na ideia de nação como um monolito, fundamentada nas noções de totalidade, homogeneidade e universalismo, que não considera o aspecto disjuntivo do social. O que o pós-colonial faz, desse modo, é evidenciar uma nova visão dessas narrativas, caracterizada pelo descentramento, dando destaque para o processo de construção do nacionalismo e das fronteiras nacionais, como também destacam Ella Shohat e Robert Stam (2006).

Indo ao encontro do que Hall afirma, está a colocação de Ana Mafalda Leite (2003) sobre a crítica pós-colonial. A autora diz que é possível fazer leituras pós-coloniais de textos considerados co-fundacionais da situação imperial, as quais possibilitam reconfigurar e atualizar os lugares de discussão. Esse campo teórico configura-se também como uma "plataforma de reinterpretação da discursividade colonial" (p. 12). Assim, o sentido cronológico do termo não se mostra suficiente.

A teoria pós-colonial traz à tona questões bastante complexas que envolvem o processo de colonização/descolonização, tais como representação, valor, universalidade, hibridação, diferença, identidade, nacionalismo, diáspora, pós-modernismo, lugar. A ficção portuguesa contemporânea, nesse sentido, tem mostrado a importância da memória para rever essas questões colocadas pelo pós-colonialismo, sobretudo para a construção da democracia, como destaca Margarida Calafate Ribeiro (2012), de forma a evidenciar as dores e as heranças da ditadura como tema. A estudiosa afirma que

Pelas análises profundas que empreendem do Portugal contemporâneo, intrinsecamente ligado à memória da ditadura que se prolonga nos nossos gestos, pensamentos e políticas e pela leitura política e ideológica que vai fazendo do que foi o colonialismo em África, que ainda 
hoje assombra, de maneira fracturante, o presente pós-colonial português, estas obras questionam os protocolos de esquecimento sobre os quais se fundou e construiu a nossa democracia, mais à procura da Europa do que de si própria, exigindo-nos uma democracia com a memória (RIBEIRO, 2012, p. 90).

A memória configura-se, então, um meio de tomada de consciência, pois possibilita a revisão do passado a partir do tempo presente. No caso do romance em questão para este trabalho, a memória do menino Benjamim não permite a ele essa tomada de consciência, mas ao leitor, que vê nela a possibilidade de ter acesso, por meio do texto, ao mundo histórico do qual o narrador-protagonista faz parte, o período da ditadura salazarista e da Revolução dos Cravos. Desse modo, O nosso reino alinha-se com a série de romances que Ribeiro (2012) define como centrados na narração de uma personagem infantil que relembra o momento histórico do fim do império português.

\section{Entre névoas identitárias}

A narrativa de Mãe tem como narrador-protagonista Benjamim, um menino de oito anos que relembra seu passado durante a ditadura de Salazar em Portugal e o momento da Revolução dos Cravos. Sua percepção infantil, ao mesmo tempo em que evoca um passado real, também apresenta ao leitor o reino de fantasias em que essa personagem vive. Manuel, seu amigo, também compartilha dessas efabulações, e é com ele que o narrador-protagonista divide suas angústias. A tensão religiosa entre salvação e transgressão norteia a narrativa, pois, não é à toa que, já nas páginas iniciais, como num alerta para o leitor sobre suas convicções, Benjamim pensa:

por isso media meus atos, temia a deus, qualquer erro poderia abrir-me as portas do inferno, que a minha convicção era a de que ficar vivo muito tempo significava merecer, longe de saber que as crianças eram anjos e pertenciam aos paraíso por direito (MÃE, 2012, p. 13-14).

Esse medo terrível, que se reflete no vigiar constante de suas atitudes, evidencia a importância que a religiosidade tem na vida desse menino. Ele sofre com a ideia que lhe foi incutida de um deus cruel, que por qualquer deslize seu pode castigá-lo. A religiosidade exacerbada também é característica de sua família, que possui nove imagens de Cristo em casa, e da vila portuguesa, não nomeada, em que vivem. Tal aspecto é fundamental para entender a identidade do colonizador português, tendo em vista que este se vê como "objecto de uma particular predileção divina”, conforme Eduardo Lourenço (2012).

Essa tônica leva a refletir sobre o momento histórico do texto, o fim do Estado Novo de Salazar, pouco antes do fim do império colonial português. A ditadura salazarista tinha 
como valores norteadores "Deus, Pátria e Família". A Igreja católica possuía forte influência sobre a população, agindo de forma a auxiliar, por exemplo, com os apelos em prol da pacificação da sociedade portuguesa. No romance de Mãe, essa instituição é representada pela sacristia úmida, com cheiro de bolor e das ratazanas que corriam rapidamente pelos seus corredores. Junto a esse ambiente angustiante, está a figura do padre, que agride Benjamim por este não querer confessar-lhe seus pecados: "quando o padre me bateu da primeira vez fiquei perplexo. fiquei uma pedra presa ao chão, os joelhos a tremer como madeira tola a querer ferir o mármore, e calei-me" (MÃE, 2012, p. 19). A descrição da sacristia e a postura do padre, diante da criança, mostram a decadência dessa instituição, que abriga ratazanas de tão obsoleta, fede a bolor por sustentar posturas que, assim como as do padre, são coercitivas e condicionadoras, instaurando o medo constante e o sentimento de culpa na população. Não é à toa que Benjamim vive constantemente assustado e o único momento em que se sente livre é quando não vai mais à igreja.

A vontade de acabar com a aflição constante em que vivia leva Benjamim a querer tentar o suicídio, como uma forma também de chegar mais rapidamente a deus, conforme suas palavras. Essa tentativa é frustrada e, então, a personagem passa a ver o mundo sob uma nova visão. Como uma espécie de messianismo, acredita ter sido escolhido por deus para viver. Por isso, decide ser santo e lutar contra os "maus". O narrador-protagonista, desse modo, evidencia um dos aspectos importantes para a construção da identidade portuguesa, na medida em que esta foi construída sobre os alicerces do mito expansionista, o qual se baseou na doutrina católica. Segundo esse imaginário, o povo português teria sido escolhido por Deus para propagar a fé católica pelo mundo. Esse mito colabora para sustentar o discurso de salvação, mantido pelos portugueses, dos povos colonizados, o qual justifica a colonização.

A comunidade, a pátria do reino de Benjamim, é preconceituosa e conservadora. Os indivíduos que vivem na vila não se questionam sobre os modos de ser e estar no mundo, contribuindo para a sustentação dos valores já impostos há muito. Percebe-se esse preconceito nas descrições que o narrador-protagonista faz e também nas exposições dos personagens. Benjamim vê Luís, o empregado de sua casa, como um monstro, descrevendo-o como um diabo de quatro patas, preto e de cabeça em chamas. Em contraposição, caracteriza o Sr. Hegarty, um inglês que cantava na igreja, da seguinte forma: "com sua voz de anjo, e cor de anjo não lhe faltava, o senhor hegarty tendia para anjo como um homem prometido ao céu." (MÃE, 2012, p. 23). Em outro momento da narrativa, ele também contrapõe a figura de Hegarty à de Darci, uma senhora de quem ele gostava muito, que veio fugida de Moçambique: "triste e preta, ela era o contrário do senhor hegarty. tanto tendesse ele para 
anjo, tenderia ela para o diabo. ou do diabo tivesse notícias no momento de se gerar." (MÃE, 2012, p. 74). Fica bastante evidente que o narrador-protagonista associa, desse modo, a cor da pele das personagens à sua oposição obsessiva entre deus e o diabo. Essa forma taxativa de percepção revela sua incapacidade de ver o outro como um sujeito que tem sua subjetividade acima de qualquer característica física, de forma a mostrar que, sua identidade também apresenta traços da identidade do colonizador, que não é capaz de ver o outro como um sujeito histórico.

Boaventura de Sousa Santos (2008) esclarece que o colonialismo português tem uma especificidade. Sendo a norma afirmada pelo colonialismo britânico, é em relação a ele que o colonialismo português é considerado periférico. Para o sociólogo, a perifericidade é dupla, pois ocorre tanto no âmbito das práticas coloniais quanto no dos discursos. No primeiro caso, a condição periférica está assentada no fato de Portugal, um país semiperiférico, depender tão fortemente da Inglaterra, tornando-se quase uma "colônia informal" desse país. No que diz respeito ao discurso, a perifericidade cabe ao fato de a história do colonialismo ter sido escrita, a partir do século XVII, em inglês, o que gera o problema da autorrepresentação do colonizador português, tendo em vista que prevalece uma "heterorrepresentação que confirma a sua subalternidade" (p. 231). Tal problema, ao que cabe ao colonizado, implica na impossibilidade ou dificuldade de este representar a si de forma diferente da posição subalterna atribuída pela representação colonial.

Nesse sentido, pode-se notar que as atitudes de Benjamim mostram esse aspecto subalterno da identidade do colonizador português, na medida em que vê o Sr. Hegarty, um inglês, branco, com a visão maniqueísta que atribui ao que é bom. Já em relação a Luís e Darci, ambos negros, provindos de ex-colônias portuguesas, atribui a representação colonial, vendo-os de uma forma negativa. Inocência Mata (2006) atenta para o fato de, mesmo após 30 anos do fim do império colonial, o discurso da nação ser o de determinar os africanos residentes em Portugal como os outros. Se esse discurso ainda é presente mesmo passado tanto tempo do fim do império, na situação histórica do texto ele se mostra muito mais forte.

As imagens de África, narradas por Benjamim, são impregnadas de uma carga semântica pejorativa, as quais incluem também essa visão do africano como o outro. Carlos, irmão de Manuel que estava na guerra em Angola, regressa e conta para os meninos que "as pretas é que gostam de foder, vocês haviam de as ver de mamas à mostra" (MÃE, 2012, p. 43). Benjamim, sem saber o que significa a palavra "foder", apenas julga que Carlos estava louco, "que a guerra fazia mal à cabeça das pessoas, isso era o que sabia perfeitamente" (MÃE, 2012, p. 43). A inocência do narrador impede que ele tenha uma visão crítica diante 
das palavras de Carlos, as quais são proferidas como uma justificativa para a perda da virgindade do jovem. Boaventura (2006) destaca que esse desejo do outro não significa ausência de racismo, mas um racismo diferente. Carlos relaciona-se com as mulheres angolanas não porque as respeita. Ele as considera meros objetos que estão à sua disposição, evidenciando esse racismo diferente de que fala Boaventura. Carlos continua sua exposição dizendo que "em angola tudo podia acontecer, porque os lugares eram ermos, esquecidos de tudo e de todos e deus não devia saber sequer que eles existiam.” (MÃE, 2012, p. 44). Apesar de ter estado em Angola, a personagem apresenta uma visão bastante estereotipada, tendo em vista que não aceita as diferenças culturais entre os países, considerando Angola, então, o lugar de uma liberdade ameaçadora, quase selvagem. Representando a identidade dominante, Carlos nega o outro, conferindo-lhe, assim, a inexistência pelo não conhecimento por parte de deus sobre esse povo.

Benjamim fica espantado ao ouvir os relatos de Carlos sobre o país de onde voltou. Começa a imaginar crianças sem escola, sob um sol muito forte, e sente pena delas. Com a convicção de que deus esqueceu de África, ele continua sua reflexão:

[...] se dona darci fosse à igreja e falasse sobre moçambique, deus, que inventou a nossa vila, saberia que sem querer inventou África, e poderia ir lá ver como as coisas eram e ordená-las a seguir o melhor caminho, como se lhes ensinasse a viver (MÃE, 2012, p. 45).

O sentimento de compaixão implica enxergar-se em uma posição de superioridade em relação ao outro, indo ao encontro do que afirmam Shohat e Stam (2006) sobre o fato de a cultura colonialista ter construído um sentimento de "superioridade ontológica" europeia em relação aos povos colonizados. Esse discurso de salvação contribuiu, assim, para um dos legados do colonialismo que se percebe no romance, a destruição de povos e culturas, tendo em vista que, a partir dessa visão do colonizador, não é possível aceitar a diferença, pois o único modo de viver é o seu. A Guerra Colonial, que é referida no romance, somente certifica a necessidade de afirmar essa superioridade.

Benjamim vive esse momento do país; no entanto, não consegue perceber sua dimensão. A passagem do 25 de Abril é retratada por ele da seguinte forma:

a professora blandina recebeu-nos com brilho nos olhos, esperou que nos sentássemos e se fizesse silêncio, e explicou, ontem os senhores que dirigiam o país foram mandados embora, agora estão pessoas do povo a trabalhar para ver quem vai dirigi-lo, e o manuel disse, é verdade, o meu pai contou-me isso à noite. estávamos em abril (MÃE, 2012, p. 102).

O discurso da professora é simples a fim de tentar ser compreensível para as crianças. Além de estar em uma fase de sua vida em que muito não pode ser compreendido, o narrador 
não possui alguém que em casa possa explicar-lhe o que acontece. Sua tia, que era a única que "prestava mais atenção às coisas complicadas" (MÃE, 2012, p. 103), já não morava mais com ele. Sua família representava bem os cidadãos de Salazar, alienados, submissos ao regime, com fome demais para pensar para além de arranjar o que comer.

Assim como Benjamim não consegue compreender a dimensão do que acontece em relação à guinada histórica da Revolução dos Cravos também não percebe, devido à sua inocência, o quanto o discurso de suas memórias carrega consigo o peso da identidade do colonizador. Assim, as imagens do outro são apresentadas no romance, de forma a exigir do leitor a tomada de consciência que a memória possibilita. Voltando-se para o passado, percebe-se nesse discurso a razão dessas representações, sendo a narrativa, então, uma forma de desconstruí-las.

\section{Considerações finais}

A teoria pós-colonial, sendo também um meio de revisar o passado colonial, possibilita a problematização da representação das identidades imbricadas nesse processo. Por estar inserido em um contexto social, o passado de Benjamim também revela o passado da nação portuguesa. Na obra de Mãe, é a partir do acesso à memória do narrador-protagonista que essa questão pode ser analisada.

Benjamim, com a inocência de sua infância, evidencia, em sua narração, a identidade do colonizador português. Tanto ele quanto Carlos colocam o leitor diante da problemática da ambivalência dessa identidade, que contém a identidade do outro, colonizado pelo colonizador e também a identidade do colonizador enquanto colonizado por outro, nesse caso, a Inglaterra. Assim, a visão apresentada dos povos de países africanos é a do colonizador, um sujeito que se vê numa posição de superioridade em relação a estes e precisa, por isso, "salvar" esses povos da selvageria em que vivem. Essa visão se aproxima da que os viajantes registram após as visitas ao Brasil, que transforma os indígenas num povo "sem fé, sem lei, nem rei."

A representação é uma das questões fundamentais no texto literário, na medida em que esse texto, enquanto discurso, insere-se nas disputas de poder devido à capacidade que tem de representar a si e ao outro. Nesse sentido, os textos literários portugueses podem reiterar as construções do outro colonizado como "sem fé, sem lei, nem rei" ou podem desconstruí-las ao evidenciar a estratégia discursiva que levou a essa representação do outro, como no caso do romance de Mãe, que desmistifica o outro colonizado, revelando o quanto ele é uma invenção 
presente na representação do português. Essa desconstrução, por envolver o mito expansionista da identidade portuguesa, põe em crise, desse modo, a própria identidade.

\section{Referências}

APPIAH, Kwame Anthony. Na casa de meu pai: a África na filosofia da cultura. Tradução de: Vera Ribeiro. Rio de Janeiro: Contraponto, 1997.

BOAVENTURA, de Sousa Santos. A gramática do tempo: para uma nova cultura política. São Paulo: Cortez, 2008.

RIBEIRO, Margarida Calafate. Itinerâncias: percursos e representações da pós-colonialidade. Porto: Edições Húmus, 2012.

FOUCAULT, Michel. A ordem do discurso. São Paulo: Edições Loyola, 1996.

HALBWACHS, Maurice. A memória coletiva. São Paulo: Centauro, 2006.

HALL, Stuart. Da diáspora - identidades e mediações culturais. Belo Horizonte: Editora UFMG, 2003.

HAMILTON, Russel. A literatura dos PALOP e a teoria pós-colonial. Via Atlântica,São Paulo, n. 3, p. 12-23. 1999.

LEITE, Ana Mafalda. Literaturas Africanas e Formulações Pós-Coloniais. Lisboa: Edições Colibri, 2003.

LOURENÇO, Eduardo. Portugal como destino: dramaturgia cultural portuguesa. Lisboa: Grandiva, 2012.

MÃE, Valter Hugo. O nosso reino. São Paulo: Editora 34, 2012.

MATA, Inocência. Estranhos em permanência: A negociação da identidade portuguesa na pós-colonialidade. In: "Portugal não é um país pequeno". Lisboa: Cotovia, 2006.

MIGNOLO, Walter. La razón postcolonial. Gragoatá, Niterói, n. 1, p. 7-29, 1996.

SHOHAT, Ella; STAM, Robert. Crítica da imagem eurocêntrica. São Paulo: Cosac Naify, 2006. 